\title{
Diet and Inflammation in Cognitive Ageing and Alzheimer's Disease
}

\author{
Andrea M. McGrattan ${ }^{1} \cdot$ Bernadette McGuinness ${ }^{2} \cdot$ Michelle C. McKinley $^{2} \cdot$ Frank Kee $^{2} \cdot$ Peter Passmore $^{2}$. \\ Jayne V. Woodside ${ }^{2} \cdot$ Claire T. McEvoy $^{2}$
}

Published online: 4 April 2019

(C) The Author(s) 2019

\begin{abstract}
Purpose of Review Nutrition is known to modulate the immune system and may alter neuroinflammatory processes implicated in the pathogenesis of Alzheimer's disease (AD) and progression of neurodegeneration. Here, we review the evidence for healthy dietary patterns and age-related cognition and discuss potential neuroinflammatory actions of diet on cognitive function.

Recent Findings Anti-inflammatory dietary patterns such as the Mediterranean diet (MD) and dietary approaches to stop hypertension (DASH) may be neuroprotective. Several dietary components consumed in the MD and DASH (omega-3 fatty acids, antioxidants and polyphenols) can inhibit neuroinflammation associated with AD. Anti-inflammatory diets may also attenuate neuroinflammation via indirect immune pathways from the gut microbiome and systemic circulation.

Summary Diet may influence cognitive ageing via several inflammatory pathways. However, data from human studies are lacking and the exact mechanisms linking diet to cognitive function remain elusive. Further dietary intervention studies are required to investigate diet-associated neurological change from the earliest through to latest stages of cognitive decline. Furthermore, incorporation of neuroimaging measures in intervention studies would advance current understanding of the mechanistic effects of dietary modification on neuroinflammation in the ageing brain.
\end{abstract}

Keywords Inflammation $\cdot$ Mechanisms $\cdot$ Pathways $\cdot$ Diet $\cdot$ Nutrients $\cdot$ Dietary patterns $\cdot$ Mediterranean diet (MD) $\cdot$ Dietary approaches to stop hypertension (DASH) $\cdot$ Pro-inflammatory diets $\cdot$ Cognition $\cdot$ Cognitive function $\cdot$ Cognitive ageing . Alzheimer's disease

\section{Introduction}

Worldwide, 50 million people are living with Alzheimer's disease $(\mathrm{AD})$ and related dementias, and this figure is projected to triple by 2050 unless preventive measures are developed [1]. Addressing modifiable risk factors is considered to be the most promising strategy to prevent $\mathrm{AD}$ [1]. In this regard, increasing evidence suggests that dietary interventions have potential to protect against cognitive decline during ageing [2-4].

This article is part of the Topical Collection on Nutrition and Aging

Claire T. McEvoy

c.mcevoy@qub.ac.uk

1 Institute of Health and Society and Newcastle University Institute of Ageing, Newcastle University, Biomedical Research Building, Campus of Ageing and Vitality, Newcastle upon Tyne NE4 5PL, UK

2 Centre for Public Health, Queen's University Belfast, Grosvenor Road, Belfast, Northern Ireland BT12 6BJ, UK
The mechanisms governing dietary influences on cognition are not clear, but inflammatory pathways are likely to be involved $[5,6]$. Inflammation has been strongly implicated in the pathogenesis of $\mathrm{AD}[7 \bullet \bullet, 8]$. Microglial macrophages in the brain become chronically activated during ageing [9], and particularly under pathological conditions [10], to promote sustained production of pro-inflammatory cytokines including interleukin-1 $\beta$, interleukin-6 (IL-6) and tumour necrosis factor- $\alpha$ (TNF- $\alpha)[8,11]$. Production of these molecules can perpetuate a cycle of neuroinflammatory processes including amyloidosis, neuronal death [10, 12], cortical thinning [13, 14], reduced brain volume [13], cerebral vascular diseaserelated events such as microbleeds and infarcts $[15,16]$ and neurodegeneration $\left[7 \bullet^{\circ}\right]$. Genetic studies provide strong evidence for a causative role of neuroinflammation in $A D$, with several mutations in microglial genes, for example, TREM2 and $\mathrm{CD} 33$, being independently associated with elevated $\mathrm{AD}$ risk [17]. Furthermore, greater numbers of activated microglial cells and cytokines have been confirmed in brain tissue from individuals with $\mathrm{AD}$ [18]. 
Diet is known to modulate the immune system [19••], and several nutrients and bioactive components can influence neuroinflammatory processes in animals. For example, polyphenols, unsaturated fats and antioxidant vitamins inhibit oxidative stress and neuroinflammation [20, 21••, 22], while saturated fat promotes inflammation, particularly in the hypothalamus [23]. However, it is not clear whether diet-induced effects on neurocognition are mediated directly by neuroinflammatory processes and/or via other immune mechanisms in vivo. An increasing body of evidence suggests that peripheral inflammation and alterations to the gut microbiome can amplify neuroinflammation and accelerate neurodegeneration $[7 \bullet \bullet, 24,25]$ and these external factors can also be influenced by diet [26].

Mechanistic studies in the brain have primarily focused on single nutrients. However, the synergistic effects of nutrients and foods when consumed together as a usual dietary pattern are likely to exert greater effects on inflammatory processes and neurodegeneration during ageing [25, 27]. There has been much interest in examining the Mediterranean diet (MD) and dietary approaches to stop hypertension (DASH) dietary patterns as potential strategies for dementia prevention due to their proven anti-inflammatory [28-30] and cardioprotective effects [31, 32]. The MD and DASH have shown promising associations with slower rate of cognitive decline [33, 34] and reduced AD risk [35-38] although results have not been consistent $[39,40]$ and evidence for a causal relationship is limited due to the small number of diet intervention studies conducted. Interestingly, more recent neuroimaging studies have shown protective effects of MD on neuronal structures and early morphological changes linked to neurodegeneration and $\mathrm{AD}$ [41-48].

This review aims to summarise available evidence to evaluate the role of MD and DASH dietary patterns for cognitive health and $\mathrm{AD}$ risk during ageing and discuss underlying inflammatory mechanisms of diet on cognitive function in humans and animal models.

\section{Dietary Patterns and Cognitive Health During Ageing}

\section{The Mediterranean Diet}

The MD describes the traditional dietary pattern consumed in Mediterranean countries and is characterised by high intake of fruits, vegetables, wholegrains, nuts and legumes; moderate intake of fish, poultry and alcohol (particularly red wine, with meals) and low intake of red and processed meats with olive oil used as the main fat source $[49,50]$. Adherence to the MD has demonstrated clear benefits for both primary [32] and secondary [51] CVD prevention. This may also be the case for cognitive function. A recent pooled analysis of available prospective data in older adults reported a beneficial association between adherence to the MD and cognitive function, especially for domains of global cognition and episodic memory [52].

Observational studies that have evaluated the MD for cognitive health are summarised in Table 1. In summary, greater concordance to the MD has been associated with better cognitive performance $[53,54,57,58,65]$, slower rate of cognitive decline $[61,66-68]$ and reduced risk of cognitive impairment $[53,55,56,61]$ and $\mathrm{AD}[36]$. However, the variable and sometimes disparate study findings $[27,59,60,62-64]$ are likely due to differences between studies in the populations investigated and methods used to assess diet and cognition. Most epidemiologic studies have examined MD adherence using a score system derived from population-specific median reported intake thresholds for each individual food component in the MD score and this approach limits the comparability of findings with other populations [53]. Furthermore, there is heterogeneity between studies with regards to the cognitive outcomes measured, follow-up time and population characteristics including baseline cognitive status.

It is possible that MD contributes to neuronal integrity across the life-course. Emerging evidence from observational studies report a link between greater MD adherence and more favourable brain structures and functions that protect against neurodegeneration including increased cortical thickness [45, 48], greater brain volumes [42], slower rate of hippocampal atrophy and improved structural connectivity $[43,44,46]$ as well as less amyloid $(\mathrm{A} \beta)$ accumulation at both midlife and older age $[41,47]$.

The effect of MD on neurocognition has been evaluated in a limited number of randomised controlled trials (RCTs). The PREDIMED study demonstrated a modest beneficial effect of increased MD adherence over 4-6 years on cognitive function in cognitively healthy adults at high CVD risk $[2,4,71]$ particularly in domains of global cognition, memory and executive function [4]. In contrast, adopting a MD over 6 months had no effect on cognitive function in healthy older Australian adults [72]. The recent NU-AGE trial also reported no benefit of a Mediterranean-style diet on cognitive function after 1 year in older European adults; however, participants with greatest MD adherence demonstrated improved global cognition and episodic memory compared to those with low adherence [73].

\section{The Dietary Approaches to Stop Hypertension Diet}

The DASH diet is an accepted non-pharmacological treatment for hypertension [31] and, like the MD, recommends a high intake of fruits, vegetables, nuts and wholegrain products. However, in contrast to a MD, DASH places greater emphasis on low fat dairy foods, low dietary sodium and does not recommend alcohol. In older adults, higher DASH scores have been associated with better cognitive function [69] and slower 


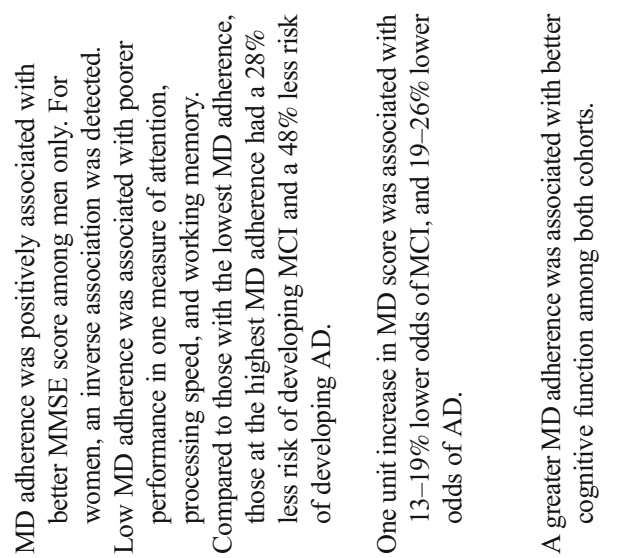

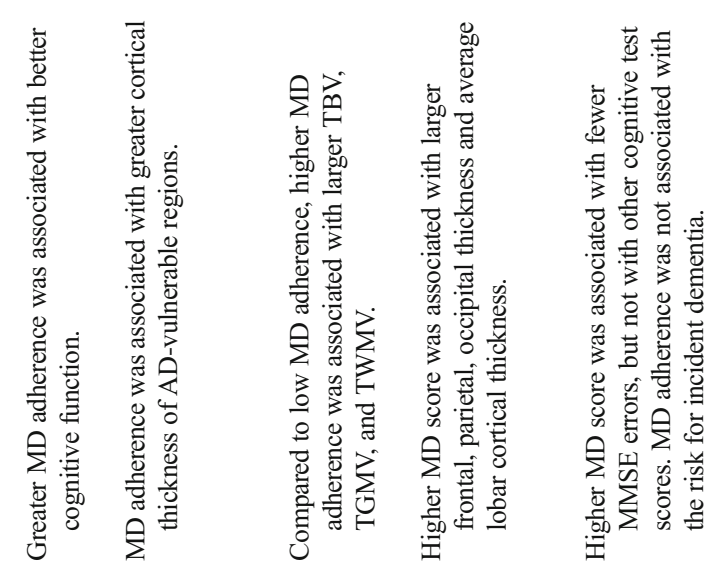

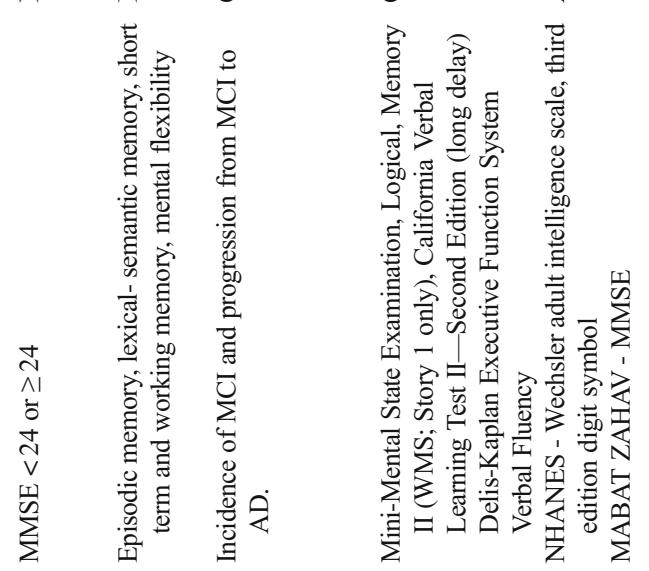

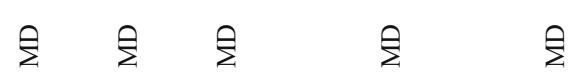

ह $\risingdotseq \equiv$

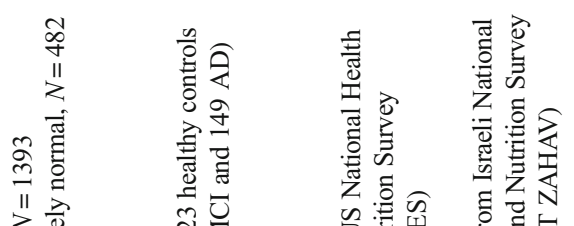

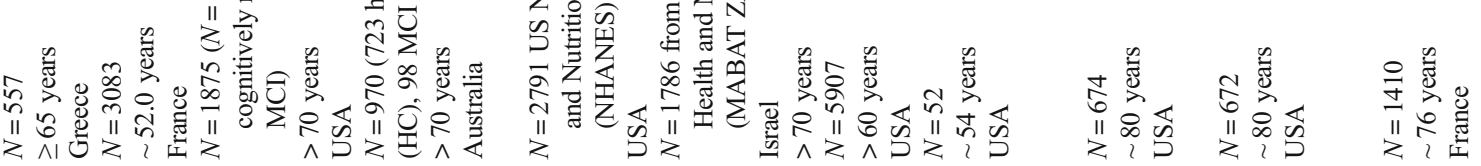

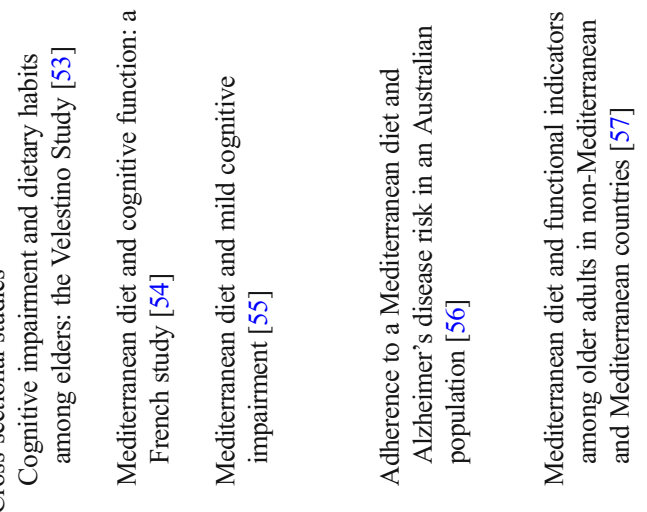

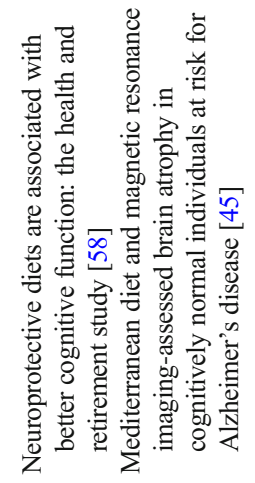

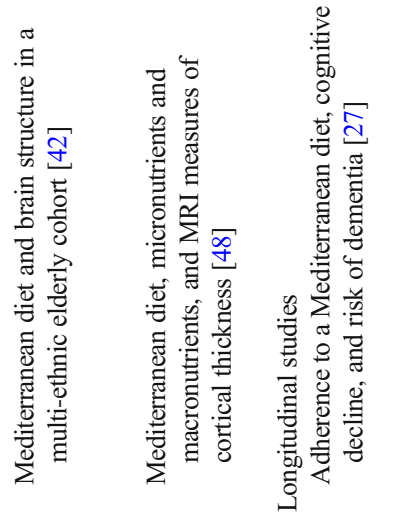




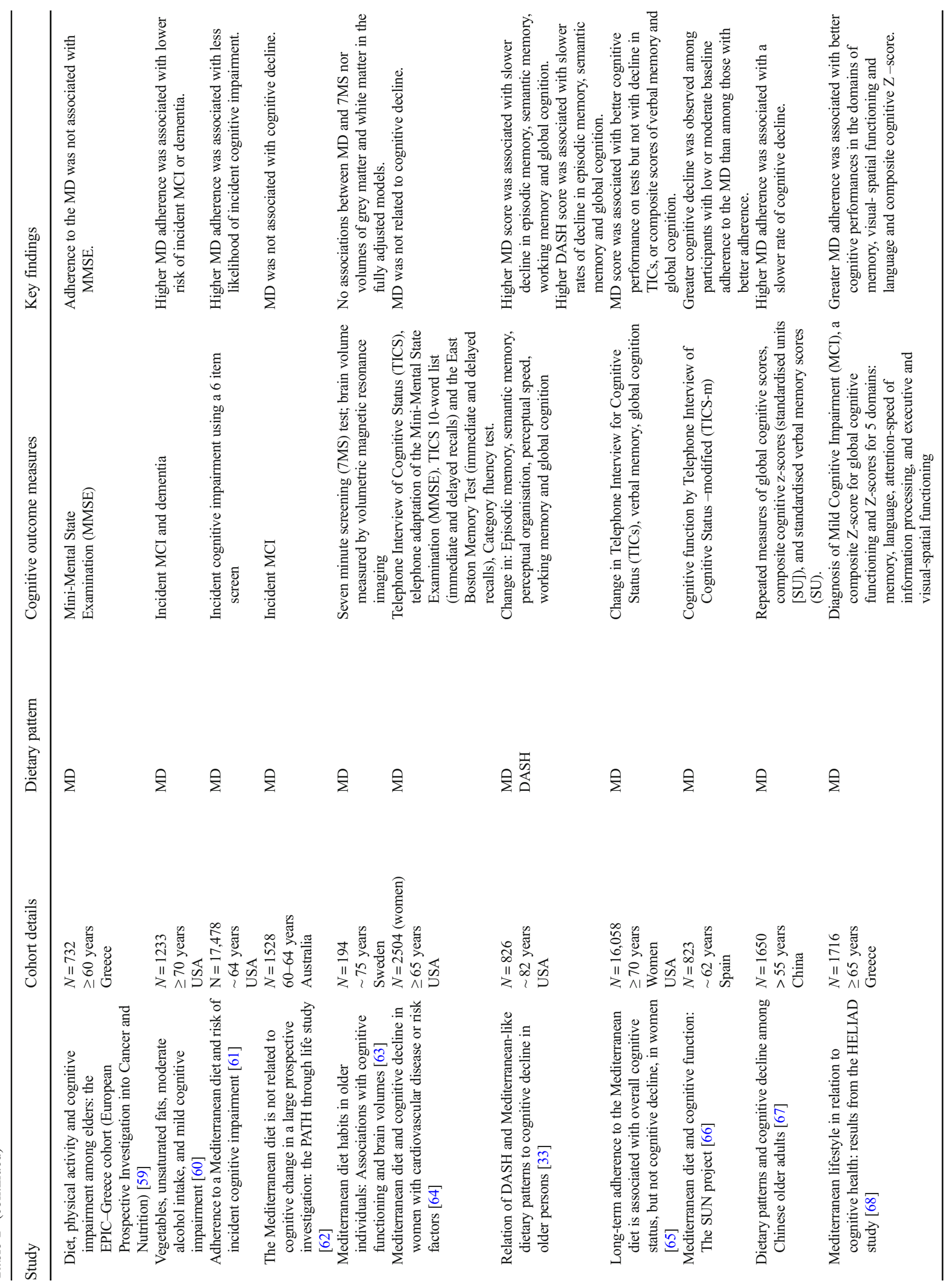




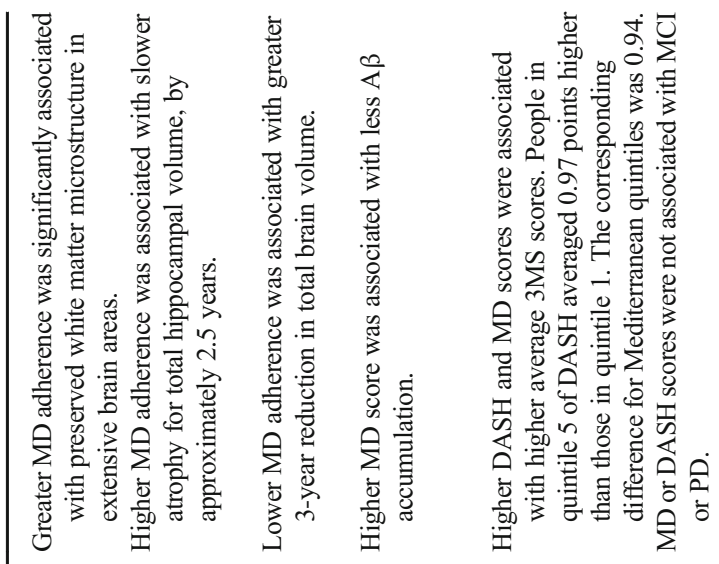

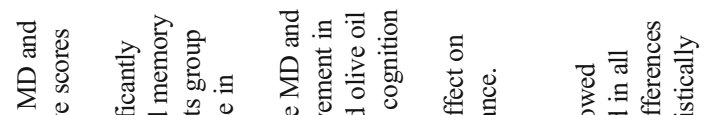

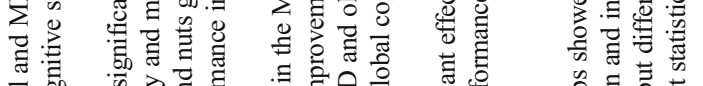

न

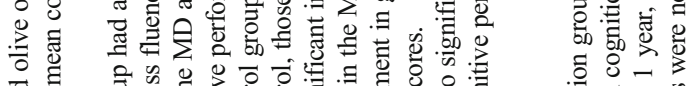

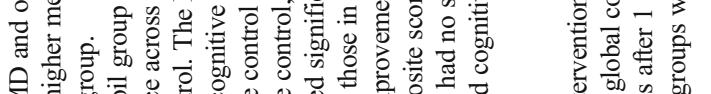

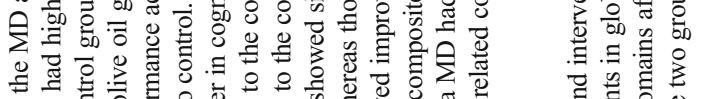

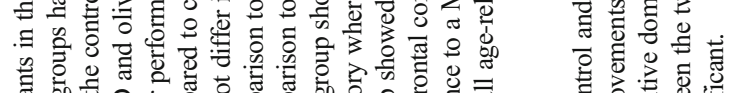

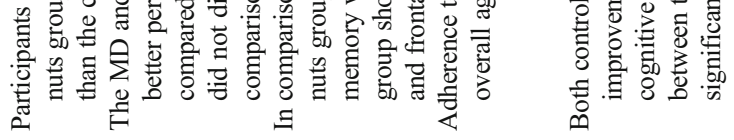

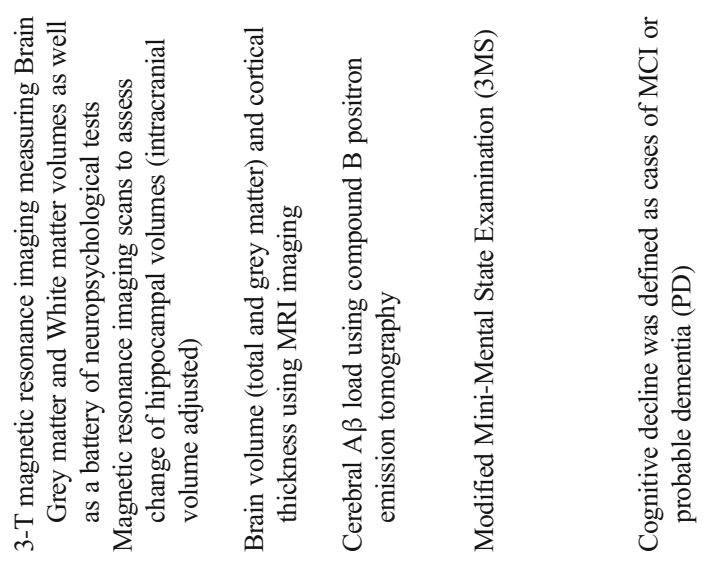

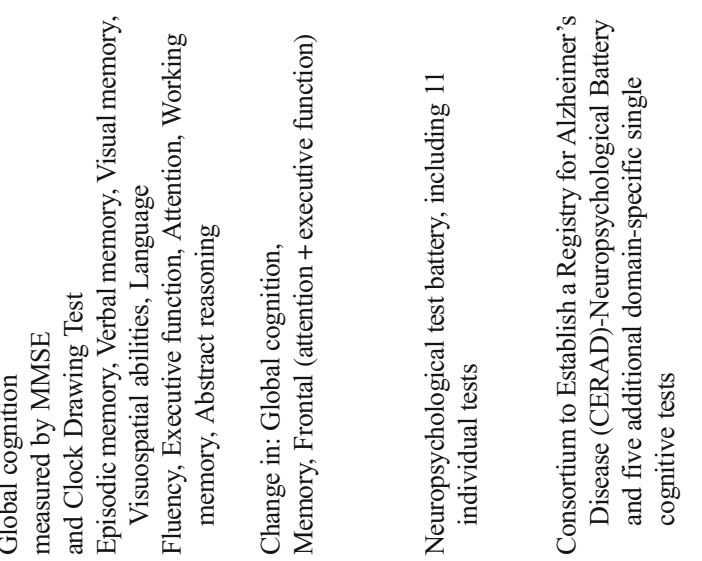

$$
\text { nan }
$$

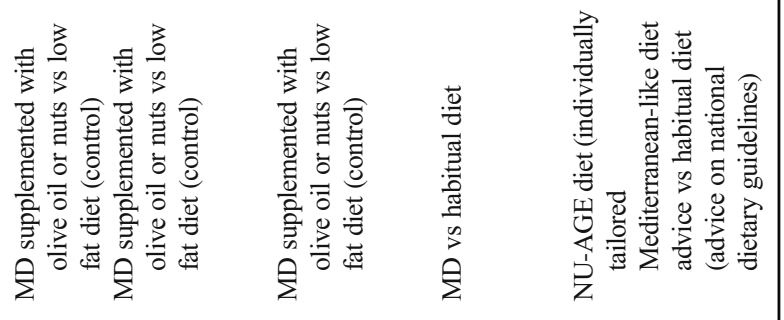

$\stackrel{n}{\stackrel{5}{\sharp}}$

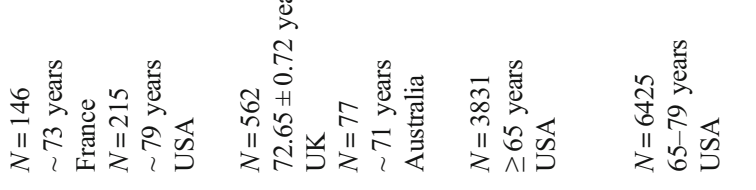

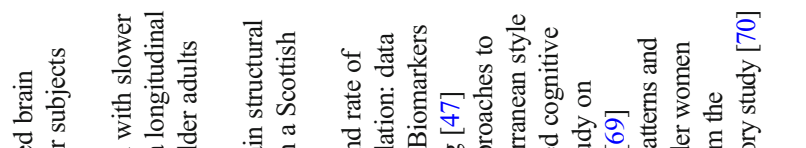

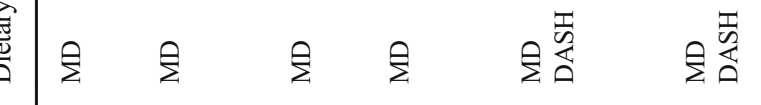

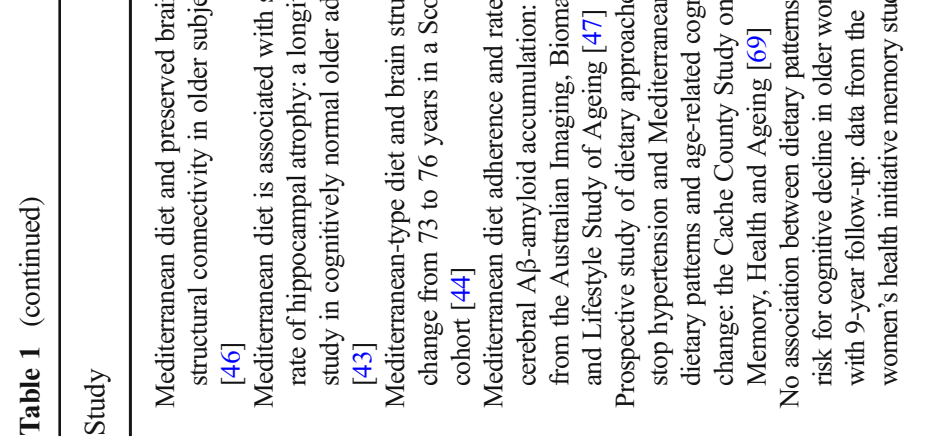

तิ

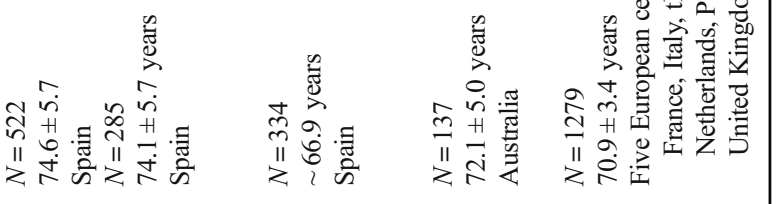

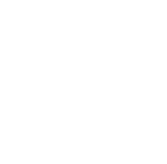

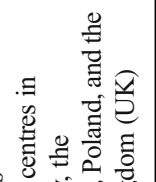

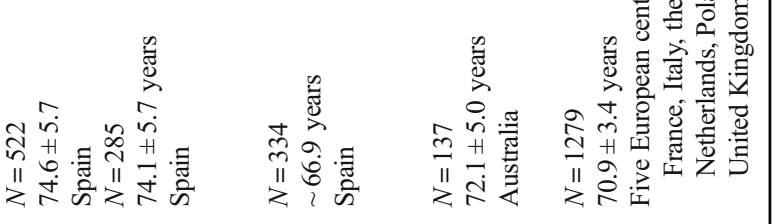

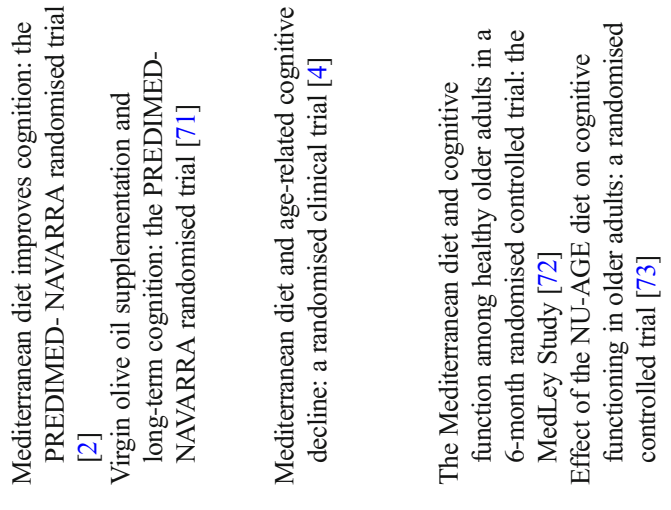


cognitive decline [33] but, again, findings have not been consistent [70]. There is limited evidence from intervention studies for an effect of DASH on neurocognition. The ENCORE study showed improved cognitive function in response to a calorie restricted DASH diet among overweight adults with hypertension [3], while preliminary 6-month data from the ENLIGHTEN study in cognitively impaired adults demonstrated no benefit of DASH diet alone on cognition, but improvement in executive function among those consuming DASH combined with aerobic exercise [74].

Collectively, the available evidence suggests that MD and DASH patterns may provide protection against neurodegeneration during ageing, with more consistent associations in favour of the MD, probably owing to a greater number of studies that have examined MD and cognition, relative to DASH or indeed other dietary patterns. Further prospective studies in diverse populations are recommended to determine relations between dietary patterns and clinically relevant measures of cognitive decline as well as incident AD. While few dietary intervention studies have been conducted, beneficial effects of MD on cognition are shown in trials of longer duration (12 months or more) $[2,4,60]$ and in participants who adhere more closely to the intervention diet [63]. Further research is required to determine the duration of dietary intervention needed for optimal effect on cognition and to identify cognitive end-point measures that can respond to subtle dietinduced changes in the ageing brain. Furthermore, intervention strategies would benefit from learning how best to support behaviour change towards a healthy dietary pattern in different population groups.

The MD and DASH dietary patterns are typically low in saturated fat, sugar and high in antioxidants, fibres and polyphenols, which have potential independent effects on brain health. It is likely that the myriad of bioactive compounds and nutrients consumed at synergistic levels within these dietary patterns exert the potential to reduce neuroinflammatory processes involved in neurodegeneration [75].

\section{Inflammatory Mechanisms of Dietary Action on Cognitive Function}

\section{Effects of Diet on Neuroinflammation}

Nutrients have important physiological roles for normal brain functioning and are transported into the brain via the bloodbrain barrier (BBB) or from the choroid plexus transport locus of the blood-cerebrospinal fluid barrier by distinct mechanisms, such as facilitated diffusion and active transport [76]. The effect of whole dietary patterns on neuroinflammation is yet to be discerned; however, animal studies have consistently reported anti-neuroinflammatory effects of several nutrients typically eaten in high amounts in MD and DASH diets. 
Antioxidants from fruit and vegetables suppress neuroinflammatory processes and neuronal apoptosis by inhibiting free radicals and cytokine production in activated microglia cells [22, 75, 77] and plant-derived flavonoids are thought to play a role in preventing neuroinflammation by downregulating transcription factor activity, e.g. $\mathrm{NF}_{-} \mathrm{B}$ and inhibiting pro-inflammatory cell signalling pathways [78, 79]. Long chain omega-3 fatty acids from fish attenuate the expression of pro-inflammatory cytokines in microglia and help to resolve inflammation in the brain $[20,80]$.

While these animal studies provide important insights into mechanistic actions of diet on neuroinflammation, it is not clear how well the findings translate to humans, due to potential differences in nutrient bioavailability and metabolism. Indeed, single nutrient supplementation has shown no cognitive benefit among older adults in the few trials that have been conducted so far $[81 \bullet, 82 \bullet]$, although positive signals have been observed for individuals with low baseline nutrient status [83] and for fish oil supplementation in early cognitive impairment [84], suggesting that population subgroups may derive cognitive benefit from nutrient supplementation.

\section{Indirect Inflammatory Actions of Diet on Neuroinflammation}

\section{Systemic Inflammation}

Increased peripheral inflammatory markers have been associated with neurodegeneration [85] and are suggested to increase neuroinflammation via neuronal and hormonal path-

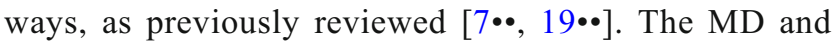
DASH diet have demonstrated anti-inflammatory effects in humans. In a recent meta-analysis of six RCTs, DASH significantly decreased serum (high-sensitivity C-reactive protein (hs-CRP) concentration (mean difference -1.01 : 95\% CI $1.64,-0.38 ; I^{2}=67.7 \%$ ) compared to usual diet which tended to be of greater magnitude in trials with longer duration [30]. The MD has been shown to decrease a broader range of inflammatory biomarkers. The PREDIMED study reported reductions in cytokines (IL-1, IL-6, IL-8, IL-12p70, CRP, TNF- $\alpha$ ) and chemokines (MCP-1 and macrophage inflammatory proteins (MIP-1 $\beta$ )) in response to a 3-month MD supplemented with either olive oil or nuts, and the anti-inflammatory effects were observed up to 5 years of intervention [28, 29]. Adoption of a MD also significantly reduced hs-CRP, IL-6, IL-7, and IL-18 in patients with the metabolic syndrome [86]. Furthermore, key components of the MD, such as oily fish and omega 3 fatty acids, as well as bioactive polyphenols found in fruits and vegetables, red wine and olive oil have also been shown to reduce pro-inflammatory markers [78, 87, 88••]. Hence, the ability of dietary patterns, particularly the MD, to decrease systemic inflammation may help to attenuate neuroinflammation.
Emerging observational data lend support to systemic inflammation as a driver between diet and neurocognition (Table 2). High pro-inflammatory dietary scores have been linked with poor cognitive performance $[91,94]$ and cognitive impairment [92, 93]. Moreover, a proinflammatory dietary pattern, based on circulating IL- 6 and characterised by higher intake of red meat, processed meat, peas and legumes, and fried food, and lower intake of whole grains has been associated with accelerated cognitive decline [89], while an inflammatory nutrient pattern derived from IL-6 and CRP levels and characterised by low intake of calcium, antioxidant vitamins, omega-3 and high intake of cholesterol, has been inversely associated with brain volume and cognitive function [90]. Further longitudinal studies are needed to evaluate whether dietary patterns based on systemic inflammatory biomarkers are related to incident $\mathrm{AD}$.

\section{The Gut Microbiome}

The human gut microbiome represents the collective genomes of 10-100 trillion microorganisms harboured in the gastrointestinal tract and is considered important for healthy immune function [95]. The ageing process and other environmental factors can result in alterations to the microbiome composition (dysbiosis) and contribute to the development of chronic lowgrade inflammation [96]. Dysbiosis stimulates excretion of endotoxins, e.g. lipopolysaccharides (LPSs) and microbial amyloids to promote permeability of the gut wall and increase peripheral circulation of proinflammatory cytokines [97]. Dybiosis has been implicated in the pathogenesis of AD by initiating and prolonging neuroinflammatory processes. Gutderived bacteria and toxins can compromise the integrity of the $\mathrm{BBB}$ and contribute to early neuroinflammatory changes and $\mathrm{AD}$ by priming microglia and impairing amyloid clearance $[24,25]$. Moreover, circulating LPSs and microbial amyloid activate innate resistance receptors, e.g. toll-like receptor (TLR) and receptor for advanced glycation end-products (RAGE) to amplify pro-inflammatory signalling and promote chronic neuroinflammation and progress neurodegeneration, particularly in brain regions sensitive to AD such as the hippocampus $[25,98]$.

Almost $60 \%$ of variation in the gut microbiome is attributable to diet [99]; therefore, modulating the gut microbiome through dietary means could be an effective approach to reduce inflammation associated with AD. However, only few studies have evaluated dietary patterns and gut microbiota. Preliminary data has shown positive associations between the MD and increased number of beneficial microbiota species, e.g. Bacteroidetes and their short chain fatty acid metabolites $[100,101]$ that have anti-inflammatory effects [26]. Further research is needed to understand the complex relationships between the gut microbiome and cognitive health and 


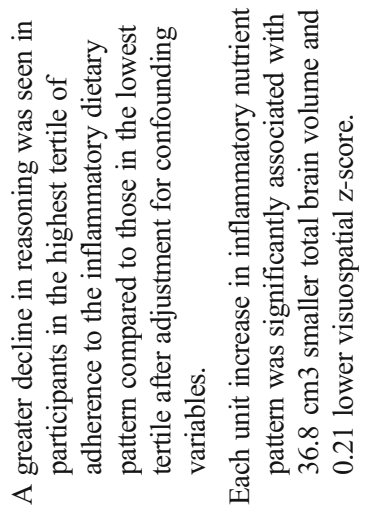

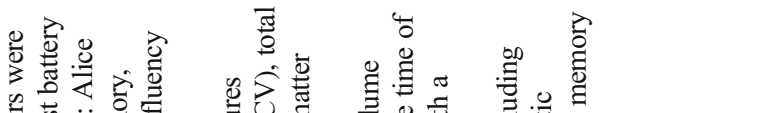

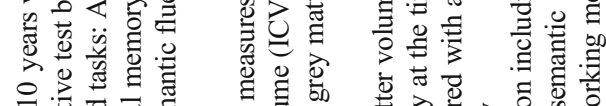

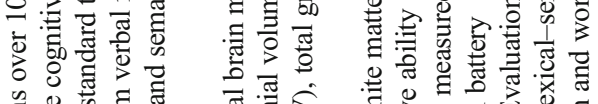

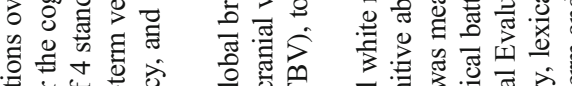

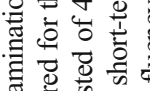

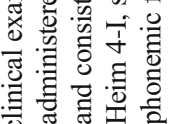

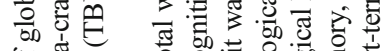

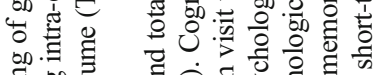

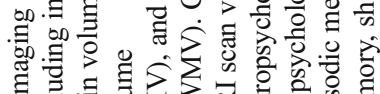

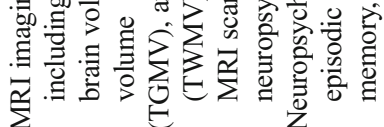

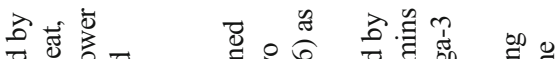

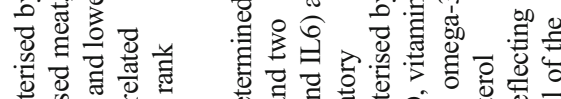

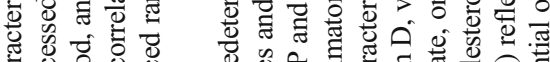

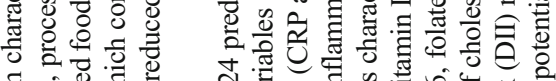

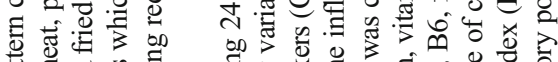

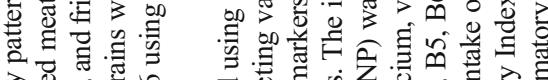

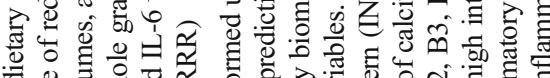

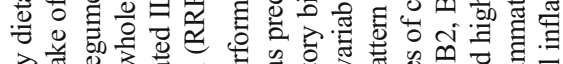

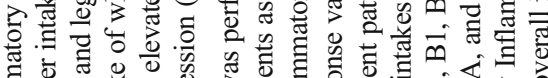

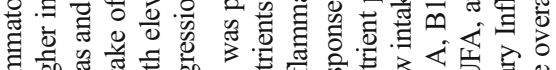

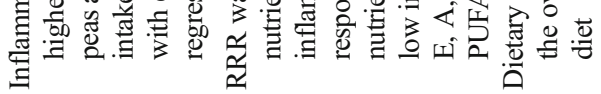

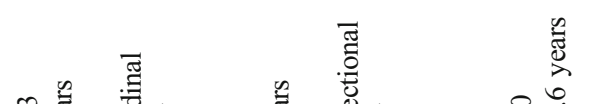

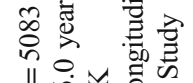

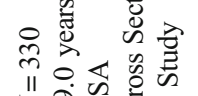

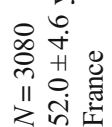

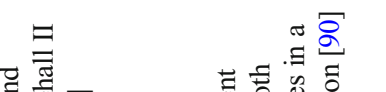

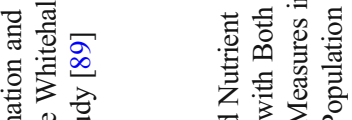

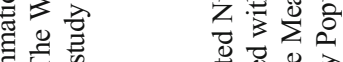

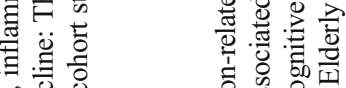

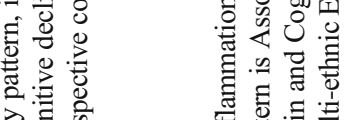

密

离 8
I⿳亠口冋!

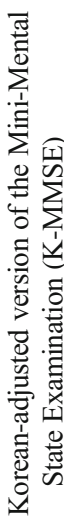

党

窟焉

च

完高

忽昆莒

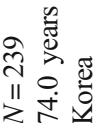

$\exists$

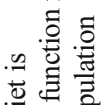

氙

可

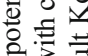

石证

魚

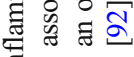

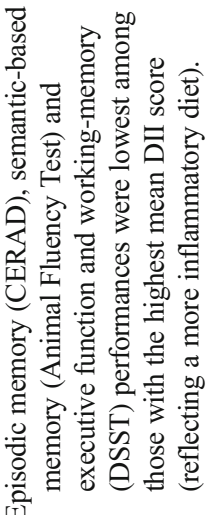

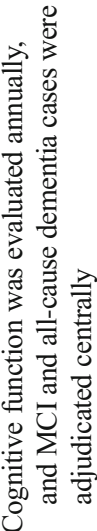

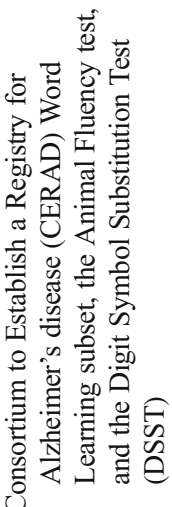

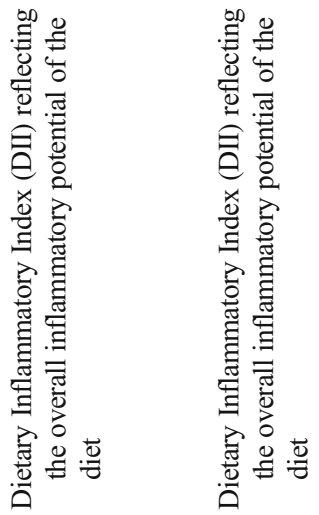

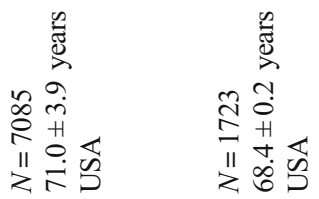

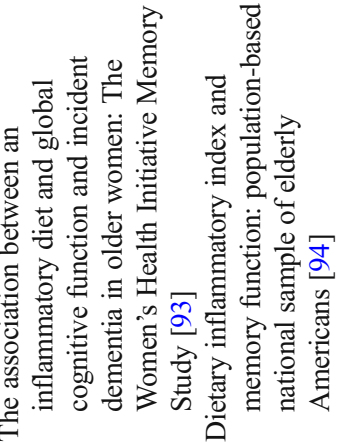


whether diet-induced effects on cognitive function are mediated by alterations in gut microbiota.

\section{Conclusion}

Given the lack of effective treatments and projected increased prevalence of $\mathrm{AD}$, there is considerable interest in understanding the contribution of neuroinflammation to the pathogenesis of $\mathrm{AD}$ in order to develop effective preventive strategies for cognitive decline.

Compelling evidence shows that nutrients and other bioactive dietary compounds influence neuroinflammatory processes leading to neurodegeneration in animals and that nutrients can act synergistically to exert greater biological effects. It is plausible that diets rich in anti-inflammatory components attenuate neuroinflammation via several immune pathways within the brain and indirectly from the gut microbiome and systemic circulation. However, data from human studies are lacking and the exact inflammatory mechanisms linking diet to cognitive function remain elusive.

Growing evidence supports a protective effect of antiinflammatory dietary patterns, especially the MD, against cognitive decline in older persons but causal associations between diet and AD remain uncertain. The evidence base has been recently strengthened by small intervention studies showing improvements in cognitive function in response to MD and calorie-controlled DASH. However, adequately powered intervention studies with larger sample sizes and longer durations are required to examine the effect of dietary modification on clinically relevant cognitive outcomes. Neuroimaging studies have shown direct beneficial associations of MD on preclinical changes associated with $\mathrm{AD}$; therefore, brain biomarkers should be considered as end-points in future intervention studies to investigate diet-associated neurological change from the earliest through to latest stages of cognitive decline. Furthermore, incorporation of PET (positron emission tomography) could allow measurement of in vivo microglia activation [102] and advance current understanding of the mechanistic effects of dietary modification on neuroinflammation in the ageing brain.

While most research attention has been given to MD and DASH, there is still much to learn about the ideal combination of foods and nutrients for optimal cognitive health during ageing. More recently, the MIND (Mediterranean-DASH diet intervention for neurodegeneration delay) dietary pattern that incorporates foods based on evidence in the diet-dementia field has shown to be more predictive of cognitive decline than the MD [103] and has also been associated with reduced $\mathrm{AD}$ risk [104]. The effect of MIND on cognitive decline is currently being evaluated in several US trials (e.g. clinicaltrials.gov Reference NCT02817074, NCT03688126) and will generate valuable data to determine whether improving diet quality is an effective strategy to improve brain health in older adults.

Funding This work was supported by the Wellcome Trust [Grant Ref 202097/Z/16/Z].

\section{Compliance with Ethical Standards}

Conflict of Interest Andrea M. McGrattan declares that she has no conflict of interest.

Bernadette McGuinness has received honoraria from Nutricia.

Michelle C. McKinley declares that she has no conflict of interest.

Frank Kee declares that he has no conflict of interest.

Peter Passmore has received honoraria from Nutricia.

Jayne V. Woodside declares that she has no conflict of interest.

Claire T. McEvoy declares that she has no conflict of interest.

Human and Animal Rights and Informed Consent This article does not contain any studies with human or animal subjects performed by any of the authors.

Open Access This article is distributed under the terms of the Creative Commons Attribution 4.0 International License (http:// creativecommons.org/licenses/by/4.0/), which permits unrestricted use, distribution, and reproduction in any medium, provided you give appropriate credit to the original author(s) and the source, provide a link to the Creative Commons license, and indicate if changes were made.

\section{References}

Papers of particular interest, published recently, have been highlighted as:

- Of importance

-• Of major importance

1. Brayne C, Miller B. Dementia and aging populations - a global priority for contextualized research and health policy. PLoS Med. 2017;14(3):e1002275. https://doi.org/10.1371/journal.pmed. 1002275 .

2. Martinez-Lapiscina EH, Clavero P, Toledo E, Estruch R, SalasSalvado J, San Julian B, et al. Mediterranean diet improves cognition: the PREDIMED-NAVARRA randomised trial. J Neurol Neurosurg Psychiatry. 2013;84(12):1318-25. https://doi.org/10. 1136/jnnp-2012-304792.

3. Smith PJ, Blumenthal JA, Babyak MA, Craighead L, WelshBohmer KA, Browndyke JN, et al. Effects of the dietary approaches to stop hypertension diet, exercise, and caloric restriction on neurocognition in overweight adults with high blood pressure. Hypertension. 2010;55(6):1331-8. https://doi.org/10.1161/ hypertensionaha.109.146795.

4. Valls-Pedret C, Sala-Vila A, Serra-Mir M, Corella D, de la Torre R, Martinez-Gonzalez MA, et al. Mediterranean diet and agerelated cognitive decline: a randomized clinical trial. JAMA Intern Med. 2015;175(7):1094-103. https://doi.org/10.1001/ jamainternmed.2015.1668.

5. Scarmeas N, Anastasiou CA, Yannakoulia M. Nutrition and prevention of cognitive impairment. Lancet Neurol. 2018;17(11): 1006-15. https://doi.org/10.1016/S1474-4422(18)30338-7. 
6. Vauzour D, Camprubi-Robles M, Miquel-Kergoat S, AndresLacueva C, Bánáti D, Barberger-Gateau P, et al. Nutrition for the ageing brain: towards evidence for an optimal diet. Ageing Res Rev. 2017;35:222-40. https://doi.org/10.1016/j.arr.2016.09.010.

7.• Heneka MT, Carson MJ, El Khoury J, Landreth GE, Brosseron F, Feinstein DL, et al. Neuroinflammation in Alzheimer's disease. Lancet Neurol. 2015;14(4):388-405. https://doi.org/10.1016/ s1474-4422(15)70016-5 A detailed review discussing the evidence for a neuroinflammatory pathway in the pathogenesis of Alzheimer's Disease.

8. Heppner FL, Ransohoff RM, Becher B. Immune attack: the role of inflammation in Alzheimer disease. Nat Rev Neurosci. 2015;16(6):358-72. https://doi.org/10.1038/nrn3880.

9. Dilger RN, Johnson RW. Aging, microglial cell priming, and the discordant central inflammatory response to signals from the peripheral immune system. J Leukoc Biol. 2008;84(4):932-9. https://doi.org/10.1189/jlb.0208108.

10. Akiyama H, Barger S, Barnum S, Bradt B, Bauer J, Cole GM, et al. Inflammation and Alzheimer's disease. Neurobiol Aging. 2000;21(3):383-421.

11. Sastre M, Klockgether T, Heneka M. Contribution of inflammatory processes to Alzheimer's disease: molecular mechanisms. 2006.

12. Block ML, Zecca L, Hong JS. Microglia-mediated neurotoxicity: uncovering the molecular mechanisms. Nat Rev Neurosci. 2007;8(1):57-69. https://doi.org/10.1038/nrn2038.

13. Gu Y, Vorburger R, Scarmeas N, Luchsinger JA, Manly JJ, Schupf $\mathrm{N}$, et al. Circulating inflammatory biomarkers in relation to brain structural measurements in a non-demented elderly population. Brain Behav Immun. 2017;65:150-60. https://doi.org/10.1016/j. bbi.2017.04.022.

14. McCarrey AC, Pacheco J, Carlson OD, Egan JM, Thambisetty M, An Y, et al. Interleukin-6 is linked to longitudinal rates of cortical thinning in aging. Transl Neurosci. 2014;5(1):1-7. https://doi.org/ 10.2478/s13380-014-0203-0.

15. Gu Y, Gutierrez J, Meier IB, Guzman VA, Manly JJ, Schupf N, et al. Circulating inflammatory biomarkers are related to cerebrovascular disease in older adults. Neurology - Neuroimmunology Neuroinflammation. 2019;6(1):e521. https://doi.org/10.1212/ NXI.0000000000000521.

16. Swardfager W, Yu D, Ramirez J, Cogo-Moreira H, Szilagyi G, Holmes MF, et al. Peripheral inflammatory markers indicate microstructural damage within periventricular white matter hyperintensities in Alzheimer's disease: A preliminary report. Alzheimers Dement (Amsterdam, Netherlands). 2017;7:56-60. https://doi.org/10.1016/j.dadm.2016.12.011.

17. Hickman S, Izzy S, Sen P, Morsett L, El Khoury J. Microglia in neurodegeneration. Nat Neurosci. 2018;21(10):1359-69. https:// doi.org/10.1038/s41593-018-0242-x.

18. Lee YJ, Han SB, Nam SY, Oh KW, Hong JT. Inflammation and Alzheimer's disease. Arch Pharm Res. 2010;33(10):1539-56. https://doi.org/10.1007/s12272-010-1006-7.

19.• Calder PC, Bosco N, Bourdet-Sicard R, Capuron L, Delzenne N, Doré $\mathrm{J}$, et al. Health relevance of the modification of low grade inflammation in ageing (inflammageing) and the role of nutrition. Ageing Res Rev. 2017;40:95-119. https://doi.org/10.1016/j.arr. 2017.09.001 A detailed review discussing the role of nutrients in modifiying low grade inflammatory processes associated with aging.

20. Devassy JG, Leng S, Gabbs M, Monirujjaman M, Aukema HM. Omega-3 Polyunsaturated Fatty Acids and Oxylipins in Neuroinflammation and Management of Alzheimer Disease. Adv Nutr (Bethesda, Md). 2016;7(5):905-16. https://doi.org/10. 3945/an.116.012187.

21.• Miquel S, Champ C, Day J, Aarts E, Bahr BA, Bakker M, et al. Poor cognitive ageing: vulnerabilities, mechanisms and the impact of nutritional interventions. Ageing Res Rev. 2018;42:40-55. https://doi.org/10.1016/j.arr.2017.12.004 An important review of single and multi-nutrient interventions targeting cognitive aging.

22. Monacelli F, Acquarone E, Giannotti C, Borghi R, Nencioni A. Vitamin C, Aging and Alzheimer's disease. Nutrients. 2017;9(7): 670. https://doi.org/10.3390/nu9070670.

23. Milanski M, Degasperi G, Coope A, Morari J, Denis R, Cintra DE, et al. Saturated fatty acids produce an inflammatory response predominantly through the activation of TLR4 signaling in hypothalamus: implications for the pathogenesis of obesity. J Neurosci. 2009;29(2):359-70. https://doi.org/10.1523/JNEUROSCI.276008.2009 .

24. Kowalski K, Mulak A. Brain-gut-microbiota Axis in Alzheimer's disease. J Neurogastroenterol Motil. 2019;25(1):48-60. https:// doi.org/10.5056/jnm18087.

25. Pistollato F, Iglesias RC, Ruiz R, Aparicio S, Crespo J, Lopez LD, et al. Nutritional patterns associated with the maintenance of neurocognitive functions and the risk of dementia and Alzheimer's disease: a focus on human studies. Pharmacol Res. 2018;131:32-43. https://doi.org/10.1016/j.phrs.2018.03.012.

26. Minihane AM, Vinoy S, Russell WR, Baka A, Roche HM, Tuohy $\mathrm{KM}$, et al. Low-grade inflammation, diet composition and health: current research evidence and its translation. Br J Nutr. 2015;114(7): 999-1012. https://doi.org/10.1017/s0007114515002093.

27. Feart C, Samieri C, Rondeau V, Amieva H, Portet F, Dartigues JF, et al. Adherence to a Mediterranean diet, cognitive decline, and risk of dementia. Jama. 2009;302(6):638-48. https://doi.org/10. 1001/jama.2009.1146.

28. Casas R, Sacanella E, Urpi-Sarda M, Corella D, Castaner O, Lamuela-Raventos RM, et al. Long-term immunomodulatory effects of a Mediterranean diet in adults at high risk of cardiovascular disease in the PREvencion con DIeta MEDiterranea (PREDIMED) randomized controlled trial. J Nutr. 2016;146(9): 1684-93. https://doi.org/10.3945/jn.115.229476.

29. Casas R, Urpi-Sardà M, Sacanella E, Arranz S, Corella D, Castañer O, et al. Anti-Inflammatory Effects of the Mediterranean Diet in the Early and Late Stages of Atheroma Plaque Development. Mediat Inflamm. 2017;2017:3674390. https://doi.org/10.1155/2017/3674390.

30. Soltani S, Chitsazi MJ, Salehi-Abargouei A. The effect of dietary approaches to stop hypertension (DASH) on serum inflammatory markers: a systematic review and meta-analysis of randomized trials. Clin Nutr. 2018;37(2):542-50. https://doi.org/10.1016/j. clnu.2017.02.018.

31. Appel LJ, Moore TJ, Obarzanek E, Vollmer WM, Svetkey LP, Sacks FM, et al. A clinical trial of the effects of dietary patterns on blood pressure. DASH collaborative research group. N Engl J Med. 1997;336(16):1117-24. https://doi.org/10.1056/ nejm199704173361601.

32. Estruch R, Ros E, Salas-Salvado J, Covas MI, Corella D, Aros F, et al. Primary prevention of cardiovascular disease with a Mediterranean diet supplemented with extra-virgin olive oil or nuts. N Engl J Med. 2018;378(25):e34. https://doi.org/10.1056/ NEJMoa1800389.

33. Tangney CC, Li H, Wang Y, Barnes L, Schneider JA, Bennett DA, et al. Relation of DASH- and Mediterranean-like dietary patterns to cognitive decline in older persons. Neurology. 2014;83(16): 1410-6. https://doi.org/10.1212/wnl.0000000000000884.

34. van de Rest O, Berendsen AA, Haveman-Nies A, de Groot LC. Dietary patterns, cognitive decline, and dementia: a systematic review. Adv Nutr. 2015;6(2):154-68. https://doi.org/10.3945/an. 114.007617.

35. Lourida I, Soni M, Thompson-Coon J, Purandare N, Lang IA, Ukoumunne OC, et al. Mediterranean diet, cognitive function, and dementia: a systematic review. Epidemiology. 2013;24(4): 479-89. https://doi.org/10.1097/EDE.0b013e3182944410. 
36. Scarmeas N, Stern Y, Tang MX, Mayeux R, Luchsinger JA. Mediterranean diet and risk for Alzheimer's disease. Ann Neurol. 2006;59(6):912-21. https://doi.org/10.1002/ana.20854.

37. Singh B, Parsaik AK, Mielke MM, Erwin PJ, Knopman DS, Petersen RC, et al. Association of mediterranean diet with mild cognitive impairment and Alzheimer's disease: a systematic review and meta-analysis. J Alzheimer's Dis: JAD. 2014;39(2): 271-82. https://doi.org/10.3233/JAD-130830.

38. Wu L, Sun D. Adherence to Mediterranean diet and risk of developing cognitive disorders: An updated systematic review and meta-analysis of prospective cohort studies. Sci Rep. 2017;7: 41317. https://doi.org/10.1038/srep41317.

39. Olsson E, Karlstrom B, Kilander L, Byberg L, Cederholm T, Sjogren P. Dietary patterns and cognitive dysfunction in a 12 year follow-up study of 70 year old men. J Alzheimers Dis. 2015;43(1):109-19. https://doi.org/10.3233/jad-140867.

40. Samieri C, Grodstein F, Rosner BA, Kang JH, Cook NR, Manson $\mathrm{JE}$, et al. Mediterranean diet and cognitive function in older age. Epidemiology. 2013;24(4):490-9. https://doi.org/10.1097/EDE. 0b013e318294a065.

41. Berti V, Walters M, Sterling J, Quinn CG, Logue M, Andrews R, et al. Mediterranean diet and 3-year Alzheimer brain biomarker changes in middle-aged adults. Neurology. 2018;90(20):e1789 e98. https://doi.org/10.1212/wnl.0000000000005527.

42. Gu Y, Brickman AM, Stern Y, Habeck CG, Razlighi QR, Luchsinger JA, et al. Mediterranean diet and brain structure in a multiethnic elderly cohort. Neurology. 2015;85(20):1744-51. https://doi.org/10.1212/WNL.0000000000002121.

43. Gu Y, Scarmeas N, Stern Y, Manly JJ, Schupf N, Mayeux R, et al. Mediterranean diet is associated with slower rate of hippocampal atrophy: a longitudinal study in cognitively normal older adults. Alzheimers Dement. 2016;12(7):P193-P4. https://doi.org/10. 1016/j.jalz.2016.06.335.

44. Luciano M, Corley J, Cox SR, Valdés Hernández MC, Craig LCA, Dickie DA, et al. Mediterranean-type diet and brain structural change from 73 to 76 years in a Scottish cohort. Neurology. 2017;88(5):449-55. https://doi.org/10.1212/WNL. 0000000000003559 .

45. Mosconi L, Murray J, Tsui WH, Li Y, Davies M, Williams S, et al. Mediterranean diet and magnetic resonance imaging-assessed brain atrophy in cognitively Normal individuals at risk for Alzheimer's disease. J Prev Alzheimers Dis. 2014;1(1):23-32.

46. Pelletier A, Barul C, Feart C, Helmer C, Bernard C, Periot O, et al. Mediterranean diet and preserved brain structural connectivity in older subjects. Alzheimers Dement. 2015;11(9):1023-31. https:// doi.org/10.1016/j.jalz.2015.06.1888

47. Rainey-Smith SR, Gu Y, Gardener SL, Doecke JD, Villemagne VL, Brown BM, et al. Mediterranean diet adherence and rate of cerebral $\mathrm{A} \beta$-amyloid accumulation: Data from the Australian Imaging, Biomarkers and Lifestyle Study of Ageing. Transl Psychiatry. 2018;8(1):238. https://doi.org/10.1038/s41398-0180293-5.

48. Staubo SC, Aakre JA, Vemuri P, Syrjanen JA, Mielke MM, Geda YE, et al. Mediterranean diet, micronutrients and macronutrients, and MRI measures of cortical thickness. Alzheimers Dement. 2017;13(2):168-77. https://doi.org/10.1016/j.jalz.2016.06.2359.

49. Bach-Faig A, Berry EM, Lairon D, Reguant J, Trichopoulou A, Dernini S, et al. Mediterranean diet pyramid today. Science and cultural updates. Public Health Nutr. 2011;14(12a):2274-84. https://doi.org/10.1017/s1368980011002515.

50. Davis C, Bryan J, Hodgson J, Murphy K. Definition of the Mediterranean diet; a literature review. Nutrients. 2015;7(11): 9139-53. https://doi.org/10.3390/nu7115459.

51. de Lorgeril M, Salen P, Martin JL, Monjaud I, Delaye J, Mamelle N. Mediterranean diet, traditional risk factors, and the rate of cardiovascular complications after myocardial infarction: final report of the Lyon diet heart study. Circulation. 1999;99(6):779-85.

52. Loughrey DG, Lavecchia S, Brennan S, Lawlor BA, Kelly ME. The impact of the Mediterranean diet on the cognitive functioning of healthy older adults: a systematic review and meta-analysis. Adv Nutr. 2017;8(4):571-86. https://doi.org/10.3945/an.117. 015495.

53. Katsiardanis K, Diamantaras AA, Dessypris N, Michelakos T, Anastasiou A, Katsiardani KP, et al. Cognitive impairment and dietary habits among elders: the Velestino study. J Med Food. 2013;16(4):343-50. https://doi.org/10.1089/jmf.2012.0225.

54. Kesse-Guyot E, Andreeva VA, Lassale C, Ferry M, Jeandel C, Hercberg S, et al. Mediterranean diet and cognitive function: a French study. Am J Clin Nutr. 2013;97(2):369-76. https://doi. org/10.3945/ajcn.112.047993.

55. Scarmeas N, Stern Y, Mayeux R, Manly JJ, Schupf N, Luchsinger JA. Mediterranean diet and mild cognitive impairment. Arch Neurol. 2009;66(2):216-25. https://doi.org/10.1001/archneurol. 2008.536.

56. Gardener S, Gu Y, Rainey-Smith SR, Keogh JB, Clifton PM, Mathieson SL, et al. Adherence to a Mediterranean diet and Alzheimer's disease risk in an Australian population. Transl Psychiatry. 2012;2(10):e164-e. https://doi.org/10.1038/tp.2012. 91.

57. Zbeida M, Goldsmith R, Shimony T, Vardi H, Naggan L, Shahar DR. Mediterranean diet and functional indicators among older adults in non-Mediterranean and Mediterranean countries. J Nutr Health Aging. 2014;18(4):411-8. https://doi.org/10.1007/s12603014-0003-9.

58. McEvoy CT, Guyer H, Langa KM, Yaffe K. Neuroprotective diets are associated with better cognitive function: the health and retirement study. J Am Geriatr Soc. 2017;65(8):1857-62. https://doi. org/10.1111/jgs.14922.

59. Psaltopoulou T, Kyrozis A, Stathopoulos P, Trichopoulos D, Vassilopoulos D, Trichopoulou A. Diet, physical activity and cognitive impairment among elders: the EPIC-Greece cohort (European prospective investigation into Cancer and nutrition). Public Health Nutr. 2008;11(10):1054-62. https://doi.org/10. 1017/s1368980007001607.

60. Roberts RO, Geda YE, Cerhan JR, Knopman DS, Cha RH, Christianson TJ, et al. Vegetables, unsaturated fats, moderate alcohol intake, and mild cognitive impairment. Dement Geriatr Cogn Disord. 2010;29(5):413-23. https://doi.org/10.1159/ 000305099 .

61. Tsivgoulis G, Judd S, Letter AJ, Alexandrov AV, Howard G, Nahab F, et al. Adherence to a Mediterranean diet and risk of incident cognitive impairment. Neurology. 2013;80(18):168492. https://doi.org/10.1212/WNL.0b013e3182904f69.

62. Cherbuin N, Anstey KJ. The Mediterranean diet is not related to cognitive change in a large prospective investigation: the PATH through life study. Am J Geriatr Psychiatry. 2012;20(7):635-9. https://doi.org/10.1097/JGP.0b013e31823032a9.

63. Titova OE, Ax E, Brooks SJ, Sjogren P, Cederholm T, Kilander L, et al. Mediterranean diet habits in older individuals: associations with cognitive functioning and brain volumes. Exp Gerontol. 2013;48(12):1443-8. https://doi.org/10.1016/j.exger.2013.10. 002.

64. Vercambre MN, Grodstein F, Berr C, Kang JH. Mediterranean diet and cognitive decline in women with cardiovascular disease or risk factors. J Acad Nutr Diet. 2012;112(6):816-23. https://doi. org/10.1016/j.jand.2012.02.023.

65. Samieri C, Okereke OI. E ED, Grodstein F. Long-term adherence to the Mediterranean diet is associated with overall cognitive status, but not cognitive decline, in women. J Nutr. 2013;143(4):4939. https://doi.org/10.3945/jn.112.169896. 
66. Galbete C, Toledo E, Toledo JB, Bes-Rastrollo M, Buil-Cosiales $\mathrm{P}$, Marti A, et al. Mediterranean diet and cognitive function: the sun project. J Nutr Health Aging. 2015;19(3):305-12. https://doi. org/10.1007/s12603-015-0441-z.

67. Qin B, Adair LS, Plassman BL, Batis C, Edwards LJ, Popkin BM, et al. Dietary patterns and cognitive decline among Chinese older adults. Epidemiology. 2015;26(5):758-68. https://doi.org/10. 1097/ede.0000000000000338.

68. Anastasiou CA, Yannakoulia M, Kontogianni MD, Kosmidis MH, Mamalaki E, Dardiotis E, et al. Mediterranean lifestyle in relation to cognitive health: results from the HELIAD study. Nutrients. 2018;10(10):1557. https://doi.org/10.3390/ nu10101557.

69. Wengreen H, Munger RG, Cutler A, Quach A, Bowles A, Corcoran C, et al. Prospective study of dietary approaches to stop hypertension- and Mediterranean-style dietary patterns and agerelated cognitive change: the Cache County study on memory, health and aging. Am J Clin Nutr. 2013;98(5):1263-71. https:// doi.org/10.3945/ajen.112.051276.

70. Haring B, Wu C, Mossavar-Rahmani Y, Snetselaar L, Brunner R, Wallace RB, et al. No Association between Dietary Patterns and Risk for Cognitive Decline in Older Women with 9-Year FollowUp: Data from the Women's Health Initiative Memory Study. J Acad Nutr Diet. 2016;116(6):921-30.e1. https://doi.org/10.1016/ j.jand.2015.12.017.

71. Martinez-Lapiscina EH, Clavero P, Toledo E, San Julian B, Sanchez-Tainta A, Corella D, et al. Virgin olive oil supplementation and long-term cognition: the PREDIMED-NAVARRA randomized, trial. J Nutr Health Aging. 2013;17(6):544-52. https:// doi.org/10.1007/s12603-013-0027-6.

72. Knight A, Bryan J, Wilson C, Hodgson JM, Davis CR, Murphy $\mathrm{KJ}$. The Mediterranean diet and cognitive function among healthy older adults in a 6-month randomised controlled trial: the MedLey study. Nutrients. 2016;8(9):579. https://doi.org/10.3390/ nu8090579.

73. Marseglia A, Xu W, Fratiglioni L, Fabbri C, Berendsen AAM, Bialecka-Debek A, et al. Effect of the NU-AGE Diet on Cognitive Functioning in Older Adults: A Randomized Controlled Trial. Front Physiol. 2018;9:349. https://doi.org/10. 3389/fphys.2018.00349.

74. Blumenthal J, Smith P, Mabe S, Hinderliter A, Lin P-H, Liao L et al. Lifestyle and neurocognition in older adults with cognitive impairments: a randomized trial. 2018.

75. Lau FC, Shukitt-Hale B, Joseph JA. Nutritional intervention in brain aging: reducing the effects of inflammation and oxidative stress. Subcell Biochem. 2007;42:299-318.

76. Spector R. Nutrient transport systems in brain: 40 years of progress. J Neurochem. 2009;111(2):315-20. https://doi.org/10.1111/j. 1471-4159.2009.06326.x.

77. Mohammadzadeh Honarvar N, Saedisomeolia A, Abdolahi M, Shayeganrad A, Taheri Sangsari G, Hassanzadeh Rad B, et al. Molecular anti-inflammatory mechanisms of Retinoids and carotenoids in Alzheimer's disease: a review of current evidence. J Mol Neurosci. 2017;61(3):289-304. https://doi.org/10.1007/s12031016-0857-x.

78. Flanagan E, Müller M, Hornberger M, Vauzour D. Impact of flavonoids on cellular and molecular mechanisms underlying agerelated cognitive decline and neurodegeneration. Curr Nutr Rep. 2018;7(2):49-57. https://doi.org/10.1007/s13668-018-0226-1.

79. Rendeiro C, Rhodes JS, Spencer JP. The mechanisms of action of flavonoids in the brain: direct versus indirect effects. Neurochem Int. 2015;89:126-39. https://doi.org/10.1016/j.neuint.2015.08. 002 .

80. Bazinet RP, Laye S. Polyunsaturated fatty acids and their metabolites in brain function and disease. Nat Rev Neurosci. 2014;15(12):771-85. https://doi.org/10.1038/nrn3820.
81. Burckhardt M, Herke M, Wustmann T, Watzke S, Langer G, Fink A. Omega-3 fatty acids for the treatment of dementia. Cochrane Database Syst Rev. 2016;(4). https://doi.org/10.1002/14651858. CD009002.pub3 An evaluation of the efficacy of omega-3 supplementation in dementia.

82. McCleery J, Abraham R, Denton D, Rutjes A, Chong LY. S AlAssaf a et al. vitamin and mineral supplementation for preventing dementia or delaying cognitive decline in people with mild cognitive impairment. Cochrane Database Syst Rev. 2018;(11). https://doi.org/10.1002/14651858.CD011905.pub2 An evalauation of the effects of vitamin and mineral supplementation on cognitive function and the incidence of dementia in people with mild cognitive impairment.

83. Morris M, Tangney C. A potential design flaw of randomized trials of vitamin supplements. 2011.

84. Freund-Levi Y, Eriksdotter M, Cederholm T, Basun H, Irving G, Garlind A et al. n-3 Fatty Acid Treatment in 174 Patients With Mild to Moderate Alzheimer Disease: OmegAD Study. 2006.

85. Koyama A, Yaffe K, O’Brien J, Blacker D, Weuve J, Metti AL. The role of peripheral inflammatory markers in dementia and Alzheimer's disease: a meta-analysis. J Gerontol: Series A. 2012;68(4):433-40. https://doi.org/10.1093/gerona/gls187.

86. Esposito K, Marfella R, Ciotola M, Di Palo C, Giugliano F, Giugliano G, et al. Effect of a mediterranean-style diet on endothelial dysfunction and markers of vascular inflammation in the metabolic syndrome: a randomized trial. JAMA. 2004;292(12): 1440-6. https://doi.org/10.1001/jama.292.12.1440.

87. Casas R, Sacanella E, Estruch R. The immune protective effect of the Mediterranean diet against chronic low-grade inflammatory diseases. Endocr Metab Immune Disord Drug Targets. 2014;14(4):245-54.

88.•• Vauzour D, Martinsen A, Laye S. Neuroinflammatory processes in cognitive disorders: Is there a role for flavonoids and $n-3$ polyunsaturated fatty acids in counteracting their detrimental effects? Neurochem Int. 2015;89:63-74. https://doi.org/10.1016/j.neuint. 2015.08.004 An imporant review of the mechanisms of omega- 3 and flavonoids on neuroinflammatory processes.

89. Ozawa M, Shipley M, Kivimaki M, Singh-Manoux A, Brunner EJ. Dietary pattern, inflammation and cognitive decline: the Whitehall II prospective cohort study. Clin Nutr. 2017;36(2): 506-12. https://doi.org/10.1016/j.clnu.2016.01.013.

90. Gu Y, Manly JJ, Mayeux RP, Brickman AM. An inflammation-related nutrient pattern is associated with both brain and cognitive measures in a multiethnic elderly population. Curr Alzheimer Res. 2018;15(5):493-501. https://doi.org/10.2174/1567205015666180101145619.

91. Kesse-Guyot E, Assmann KE, Andreeva VA, Touvier M, Neufcourt L, Shivappa N, et al. Long-term association between the dietary inflammatory index and cognitive functioning: findings from the SU.VI.MAX study. Eur J Nutr. 2017;56(4):164755. https://doi.org/10.1007/s00394-016-1211-3.

92. Shin D, Kwon SC, Kim MH, Lee KW, Choi SY, Shivappa N, et al. Inflammatory potential of diet is associated with cognitive function in an older adult Korean population. Nutrition. 2018;55-56: 56-62. https://doi.org/10.1016/j.nut.2018.02.026.

93. Hayden KM, Beavers DP, Steck SE, Hebert JR, Tabung FK, Shivappa N, et al. The association between an inflammatory diet and global cognitive function and incident dementia in older women: the Women's Health Initiative memory study. Alzheimers Dement. 2017;13(11):1187-96. https://doi.org/10. 1016/j.jalz.2017.04.004.

94. Frith E, Shivappa N, Mann JR, Hebert JR, Wirth MD, Loprinzi PD. Dietary inflammatory index and memory function: population-based national sample of elderly Americans. Br J Nutr. 2018;119(5):552-8. https://doi.org/10.1017/ s0007114517003804. 
95. Clemente JC, Manasson J, Scher JU. The role of the gut microbiome in systemic inflammatory disease. Bmj. 2018;360: j5145. https://doi.org/10.1136/bmj.j5145.

96. Power SE, O'Toole PW, Stanton C, Ross RP, Fitzgerald GF. Intestinal microbiota, diet and health. Br J Nutr. 2014;111(3): 387-402. https://doi.org/10.1017/s0007114513002560.

97. Kaliannan K, Wang B, Li XY, Kim KJ, Kang JX. A hostmicrobiome interaction mediates the opposing effects of omega6 and omega- 3 fatty acids on metabolic endotoxemia. Sci Rep. 2015;5:11276. https://doi.org/10.1038/srep11276.

98. Sochocka M, Donskow-Łysoniewska K, Diniz BS, Kurpas D, Brzozowska E, Leszek J. The gut microbiome alterations and inflammation-driven pathogenesis of Alzheimer's disease - a critical review. Mol Neurobiol. 2018;56:1841-51. https://doi.org/10. 1007/s12035-018-1188-4.

99. Jin M, Qian Z, Yin J, Xu W, Zhou X. The role of intestinal microbiota in cardiovascular disease. J Cell Mol Med. 2019;0(0). https:// doi.org/10.1111/jcmm. 14195 .

100. Garcia-Mantrana I, Selma-Royo M, Alcantara C, Collado MC. Shifts on Gut Microbiota Associated to Mediterranean Diet Adherence and Specific Dietary Intakes on General Adult
Population. Front Microbiol. 2018;9(890). https://doi.org/10. 3389/fmicb.2018.00890.

101. Gutierrez-Diaz I, Fernandez-Navarro T, Sanchez B, Margolles A, Gonzalez S. Mediterranean diet and faecal microbiota: a transversal study. Food Funct. 2016;7(5):2347-56. https://doi.org/10. 1039/c6fo00105j.

102. Cagnin A, Kassiou M, Meikle SR, Banati RB. Positron emission tomography imaging of neuroinflammation. Neurotherapeutics. 2007;4(3):443-52. https://doi.org/10.1016/j.nurt.2007.04.006.

103. Morris MC, Tangney CC, Wang Y, Sacks FM, Barnes LL, Bennett DA, et al. MIND diet slows cognitive decline with aging. Alzheimer's Dement : J Alzheimer's Assoc. 2015;11(9):1015-22. https://doi.org/10.1016/j.jalz.2015.04.011.

104. Morris MC, Tangney CC, Wang Y, Sacks FM, Bennett DA, Aggarwal NT. MIND diet associated with reduced incidence of Alzheimer's disease. Alzheimer's Dement: J Alzheimer's Assoc. 2015;11(9):1007-14. https://doi.org/10.1016/j.jalz.2014.11.009.

Publisher's Note Springer Nature remains neutral with regard to jurisdictional claims in published maps and institutional affiliations. 